\title{
LA VOZ DE NADIE. SOBRE EL PENSAMIENTO DEL CUERPO EN LA LITERATURA LATINOAMERICANA RECIENTE
}

THE VOICE OF NO ONE. ON THE THOUGHT OF THE BODY IN RECENT

LATIN AMERICAN LITERATURE

\author{
JULIETA YeLIN \\ CONICET-Universidad Nacional de Rosario \\ julietayelin@conicet.gov.ar
}

\begin{abstract}
RESUMEN: El artículo se propone indagar, a partir de la lectura de algunos pasajes de ficciones de la literatura latinoamericana reciente, la emergencia de lo que llamamos pensamiento del cuerpo. Partimos de la hipótesis de que los textos dialogan con el estado actual de la reflexión en torno de las políticas de lo viviente, y que lo hacen a través de experimentaciones en las que el cuerpo no es solo un centro organizador del relato -cuerpos enfermos, putrefactos, metamorfoseados, desindividualizados-, sino también una lente, una perspectiva. De este modo, la literatura interviene activamente en el horizonte de discusiones en torno del estatuto contemporáneo del cuerpo, y lo hace concibiéndolo no solo como un campo de batalla biopolítica, sino también como una herramienta creadora y transformadora.
\end{abstract}

PALABRAS CLAVE: Literatura latinoamericana; pensamiento; cuerpo; biopolítica; biopoética

ABSTRACT: The article aims to investigate, parting from the reading of some passages of fictions of recent Latin American literature, the emergence of what we call thought of the body. We start from the hypothesis that the texts dialogue with the current state of reflection on the politics of the living, and that they do so through experimentations in which the body is not only an organizing center of the story -sick, rotten, metamorphosed, disindividualized bodies- but also a lens, a perspective. In this way, literature actively intervenes in the horizon of discussions around the contemporary status of the body, and does so by conceiving it not only as a biopolitical battlefield, but also as a creative and transforming tool.

KeyWords: Latin American Literature; Thinking; Body; Biopolitics; Biopoetics

$$
\text { to }
$$




\begin{abstract}
"Dadme, pues, un cuerpo": esta es la fórmula de la inversión filosófica. El cuerpo ya no es el obstáculo que separa al pensamiento de sí mismo, lo que este debe superar para conseguir pensar. Por el contrario, es aquello en lo cual el pensamiento se sumerge o debe sumergirse, para alcanzar lo impensado, es decir, la vida.

Gilles Deleuze, La imagen-tiempo. Estudios sobre cine 2
\end{abstract}

Estas páginas tienen como fin indagar, a través de la lectura de algunos pasajes de ficciones de la literatura latinoamericana reciente, la emergencia de lo que, por el momento, llamaremos pensamiento del cuerpo, en los dos sentidos que admite la expresión: como cuerpo pensante y como pensamiento de lo corpóreo. Partimos de la hipótesis de que en las últimas décadas ha tenido -y sigue teniendo- lugar una reestructuración del imaginario del cuerpo que está, sin duda, estrechamente ligada a las transformaciones sufridas por la noción de subjetividad. Ciertamente, no se trata de una novedad teórica -todo se enraíza, en definitiva, en el terreno del corpus nietzscheano-, pero es posible registrar un creciente número de intervenciones críticas que reflexionan sobre los efectos estéticos y políticos de dichos cambios; voces que solicitan, como una suerte de programa implícito colectivo, la elaboración de nuevas herramientas metodológicas que ayuden a calibrar su magnitud y a estudiar sus matices.

Los trabajos que Rosi Braidotti ha publicado en los últimos años en torno de estas transformaciones albergan algunas de las propuestas más interesantes y productivas. Su conceptualización de la "subjetividad nómada" como resultado de una serie de interrelaciones en las que juegan un papel crucial los cuerpos y la afectividad resultan pertinentes y sugerentes para aproximarse a aquellas ficciones en las que el cuerpo constituye el nexo que articula escritura y vida. En esa articulación se despliegan las fuerzas de lo imaginario, ese "vínculo invisible, pero fortísimo, que conecta el dentro con el fuera de sí", esa "cola simbólica que se y nos pega a un contexto social que nos constituye como sujetos, red de afectos tanto libidinales como sociales, que funciona y debe ser analizada en base a las relaciones de poder" (Braidotti 2018: 49-50). Para escribir la vida, se podría decir, es necesario poner el cuerpo; y esto implica no solo tematizarlo, examinarlo, interrogarlo, sino también hacerlo actuar, pensar, imaginar, producir sentido y sinsentido en la escritura. Si la definición de imaginario que propone Braidotti resulta tan adecuada para pensar el cuerpo es porque lo imaginario habita precisamente en y entre los cuerpos; es el espacio transicional al interior del cual se constituyen y cobran sentido. ${ }^{1}$ Pues no existe algo así como un cuerpo natural, pre-cultural, sino que su existencia emana precisamente de la caída de la dicotomía naturaleza-cultura. La noción de subjetividad nómada pretende, así, nombrar aquello que excede las categorías identitarias modernas, en tanto

\footnotetext{
1 Para un análisis de las diversas reformulaciones del concepto de imaginario en el marco de las Ciencias humanas y sociales de la segunda mitad del siglo xx, véase Belinsky (2007).
} 
lo que caracteriza al pensamiento filosófico y político contemporáneo es la inclusión del cuerpo, de la vida, como clave para pensar la experiencia humana. ¿Cómo no sería, entonces, necesario un nuevo léxico crítico para comprender lo que (nos) está sucediendo y para propiciar el desarrollo de una biopolítica afirmativa (Esposito 2011: 50)? Como señala la propia Braidotti, "la invención de conceptos nuevos es indisociable del proceso de reestructuración del imaginario" (2018: 50).

En ese camino se orienta toda una vertiente de la filosofía política reciente, que procura reflexionar acerca de las consecuencias que las transformaciones imaginarias y conceptuales de la subjetividad tienen sobre las formas de legislación y gubernamentalidad en nuestras sociedades, y también lo hacen, en el campo de la cultura, la teoría poscolonial, los estudios de género y todas aquellas investigaciones orientadas a examinar las modificaciones introducidas sobre nuestros esquemas corporales -concretos y virtuales- por el desarrollo, en esta etapa del capitalismo avanzado, de las biotecnologías, la ingeniería genética y las tecnologías de la información y la comunicación. Todas estas perspectivas intervienen activamente en las políticas de los cuerpos: permiten comprender mejor cómo son regulados y cómo se generan formas de resistencia que transforman, a su vez, aquellas regulaciones. Manifestaciones políticas y performances artísticas - muchas veces unidas de modo indiscernible-son incorporadas, así, al debate en torno del estatuto del cuerpo en la contemporaneidad, y ofrecen, en ocasiones, modalidades alternativas de participación. El cuerpo se convierte, de este modo, en un territorio en disputa cuya soberanía depende en buena medida del juego de sus definiciones.

Ahora bien, la mayor parte de dichas discusiones se apoyan en la premisa de una cierta direccionalidad de los discursos y las acciones. Aunque no siempre la intencionalidad de la intervención coincida plenamente con sus efectos, existe, evidentemente, en los movimientos feministas, ecologistas o de lucha por la justicia social, una voluntad transformadora -el activismo como "pasión política fundamental" (Braidotti 2018: 106)- orientada a un conjunto de reivindicaciones políticas -cuando Braidotti lee la potencia creadora y performativa del grupo feminista de punk rock Pussy Riot, lo hace partiendo de la evidencia de que ellas se proponen denunciar un determinado estado de cosas con el fin de modificarlo-. Nos interesa aquí saber qué sucede cuando los materiales con los que tratamos de leer el estado del pensamiento en torno del cuerpo y las tensiones que lo atraviesan no son un conjunto de propuestas artísticas emancipadoras sino una serie de textos ficcionales experimentales, difíciles de adscribir a una corriente de pensamiento o a un programa creativo determinado; $y$, también, teniendo en cuenta esta constatación, cómo sería deseable tratarlos para evitar manipularlos e instrumentalizarlos. ¿Cómo librarlos de una función ejemplificadora; cómo hacer para no reducirlos a pura representación? El mayor desafío de estos diálogos transdisciplinares parece ser el de poner las ficciones a producir pensamiento; pensamiento de las subjetividades nómadas o, en términos foucaultianos, de los procesos de subjetivación; pensamiento de los límites entre los cuerpos, de sus capacidades de impedir o intensificar sus poderes de interactuar con los demás 
y con lo demás. En las novelas de la literatura latinoamericana reciente a las que nos dedicaremos en estas páginas, tiene lugar un pensamiento del cuerpo que no se realiza mediante el despliegue de una conciencia de lo corporal, ni tampoco de su objetivación como pura materialidad en contacto, sino que es, precisamente, un espacio intermedio "donde se activan afectos y se estructuran influencias que desplazan la distinción entre el interior y el exterior del sujeto" (Braidotti 2018: 38). Un espacio que se abre por el lenguaje y en el lenguaje. Escribir el cuerpo es, en estas ficciones, explorar el mundo desde la perspectiva imaginaria de una forma-de-vida.

\title{
1. ESCRITURA Y FORMA-DE-VIDA
}

\author{
Esto dijo ella: \\ Ya nunca más vamos a ser las historias que nos con- \\ tamos. \\ No estaba a su lado, pero la escuchaba como un su- \\ surro en su cerebro. \\ Ya nunca vamos a poder ser los cuerpos, dijo. \\ Era la espesura de una voz, electricidad en el aire, en \\ lo que ya no alcanzaba a divisar. \\ Maximiliano Barrientos, En el cuerpo una voz
}

El cuerpo es uno de los conceptos nodales del pensamiento biopolítico. Michel Foucault ha dedicado buena parte de su producción, y en especial sus últimos años, a una reflexión sobre la dimensión política del cuerpo, sobre sus formas de sujeción y resistencia. Percibió con lucidez que la vida biológica es aquello que, en un mismo gesto, la política incluye y excluye para hacer posible la emergencia de una vida humana discernible de la del resto de los vivientes (Foucault 2002: 135-37). En la definición del cuerpo está en juego, por tanto, el problema de la animalidad del ser humano, es decir, de nuestra íntima relación con la fuerza anómala y anónima de la vida. Las teorizaciones posteriores en el campo de la biopolítica han permitido comprender también que el establecimiento de la relación bíos-zoé solo es posible mediante la experiencia del pensamiento, que es el modo en que nuestra forma de vida deviene forma-de-vida; por tanto, la experiencia corporal no es menos relevante que -ni puede deslindarse de- el ejercicio teórico para comprender nuestro devenir-humano, eso que Giorgio Agamben ha llamado acontecimiento antropogénico: un proceso siempre en curso que remite a la fractura entre vida y lengua, entre el viviente y el hablante. ${ }^{2}$ Vida corpórea y pensamiento no son, desde esta perspectiva, realidades discernibles, sino indisolubles condiciones de posibilidad para la emergencia de lo humano.

\footnotetext{
2 "El devenir humano del hombre implica la experiencia incesante de esta división y, al mismo tiempo, de la igualmente incesante nueva rearticulación histórica de lo que así había sido dividido" (Agamben 2017: 373).
} 
Siguiendo el arco que se traza entre las reflexiones foucaultianas acerca de las formas de vida -contenidas, de modo más o menos explícito, tanto en sus análisis del poder disciplinario y en la conceptualización de la noción de biopolítica como en su definición de los procesos de subjetivación y del ejercicio del cuidado de sí- y los trabajos filosófico-políticos más recientes de Agamben (2017) y Roberto Esposito (2016) en torno de las transformaciones que han sufrido las representaciones, el valor y las funciones del cuerpo en algunos momentos de la historia de la filosofía en Occidente, parece inevitable interrogarse acerca del rol que el pensamiento artístico -creador y crítico- ha cumplido y sigue cumpliendo en la deriva de esos cambios; o, para formularlo de modo más específico, ¿cómo se podría vincular la escritura literaria con la noción de forma-de-vida?

Con el fin de abordar el anudamiento literatura-forma-de-vida, hemos delineado, en una serie de trabajos recientes, la noción de biopoética (Yelin 2015a, 2016, 2017), que procura brindar un marco conceptual para circunscribir y analizar los procedimientos mediante los cuales se vuelve inoperosa en el lenguaje la distinción bíos/zoé. Nos gustaría formular aquí una hipótesis que vincule esa noción en proceso de elaboración con la idea que rige estas páginas; esto es, que el pensamiento literario latinoamericano reciente dialoga con el estado actual de la reflexión en torno de las políticas de lo viviente, y que lo hace a través de la experimentación con escrituras del cuerpo en las que este no solo es un centro organizador del relato -cuerpos enfermos, putrefactos, metamorfoseados, desindividualizados- sino también una lente, una perspectiva. ${ }^{3}$ Veamos, entonces, la tesis en cuestión: la lectura biopoética sería aquella que hace lugar, o que produce, un pensamiento del cuerpo, permitiendo, así, la observación de lo humano como proceso, es decir, la percepción de subjetividades todavía-nohumanas. El pensamiento del cuerpo podría ser entendido, desde este punto de vista, como una vía de aproximación a la forma-de-vida, una exploración de los procesos mediante los cuales los humanos están continuamente autoafirmándose. La labor del escritor y del crítico se conciben, en este marco, como prácticas generadoras de las condiciones para que el pensamiento del cuerpo tenga lugar, para que la vida (se) piense por sí misma. En El uso de los cuerpos -título que evoca el del segundo tomo de la Historia de la sexualidad, El uso de los placeres-, Agamben se refiere a esta particular relación entre creación humana y creación de lo humano: "Si el pensamiento, las artes, la poesía y, en general, las praxis humanas tienen algún interés, es porque hacen girar arqueológicamente en vacío a la máquina y las obras de la vida, de la lengua, de la economía y de la sociedad para remitirlas al acontecimiento antropogénico, porque en ellas el devenir humano del hombre nunca se ha realizado de una vez y para siempre, jamás deja de advenir" (2017: 373).

¿Qué significa, traducido a términos literarios, hacer girar en vacío a la máquina y las obras de la vida y cómo se puede -si es que se puede-rastrear ese juego en la escritura? ¿Cuál es la relevancia de los cuerpos en ese juego, y cómo participan del movimiento de remitencia al acontecimiento antropogénico? Pa-

3 Para un mayor desarrollo de este punto véase Yelin (2017). 
reciera que aquello que la crítica, a partir de la propuesta de Alberto Giordano ha llamado giro autobiográfico -"un movimiento perceptible no solo en la publicación de escrituras íntimas (diarios, cartas, confesiones) y en la proliferación de blogs de escritores, sino también en relatos, en poemas y hasta en ensayos críticos que desconocen las fronteras entre literatura y 'vida real'" (2008: 13)hubiera tomado en los últimos años, al menos en el ámbito del pensamiento literario latinoamericano, un matiz singular: una suerte de impulso experimental ligado a la indagación de ritmos y afecciones de la vida corporal, a la exploración de los movimientos y manifestaciones de esa vida muda que, sin embargo, no deja de producir voces y sentidos. Como si las llamadas "escrituras del yo" se hubieran deslizado, movidas por las intermitentes señales de un objeto esquivo -el yo lingüístico, humano, subjetivo, que han descripto y trajinado las ciencias sociales y humanas a lo largo del siglo $x x$ - hacia las escrituras de la vida, haciendo entrar en el juego todos los aspectos negados o marginados tradicionalmente por las filosofías del sujeto. Un movimiento que incorpora, como clave creadora e interpretativa, el pensamiento corpóreo, instituyendo "una nueva ética de las subjetividades encarnadas" (Braidotti 2018: 26). Por esa inclusión cobran una relevancia inusitada los afectos, es decir, los deseos y las ideas singulares que producen el crecimiento o el decrecimiento de las potencias de los cuerpos, su capacidad de afectar y de ser afectados, su intensidad.

Daniel Link, uno de los críticos y escritores que hace alrededor de una década intervino activamente de las discusiones en torno del giro autobiográfico en la literatura actual, registra dicho desplazamiento y lo asocia a una voluntad de registro del entorno, y de las sensaciones que el contacto con él produce, que describe como una "voracidad de lo concreto". La expresión hace pensar, más que en un impulso autobiográfico, en un giro auto-zoográfico; la búsqueda de una experiencia de sí en las afecciones -en el sentido de afecto, apego o inclinación, pero también en el de alteración y padecimiento- de la vida corporal. Link se pregunta por qué se escucha tanto "yo" en la literatura que leemos, y se responde que cuando lee "yo", registra "referencias a un mundo concreto (existente o no)." Y observa: "Esa voracidad por lo concreto es lo que resulta llamativo. Como quien dijera que lo que en este momento nos atraviesa es la necesidad de inscribir el propio cuerpo en relación con todo lo que existe (porque la voracidad por lo concreto es correlativa al terror a la desaparición)" (Link 2009). A partir de una breve observación acerca de la autorreferencialidad en las escrituras del presente, Link señala la emergencia, en los textos de sus contemporáneos, de, por un lado, una evidente pulsión intimista -que atraviesa a la literatura y también, en cierta medida, a la crítica de nuestro tiempo-y, por otro lado, la búsqueda ansiosa de contacto con una realidad perceptiva -lo que llama "mundo concreto" - que conjure la inconsistencia de la identidad más allá de sus 
manifestaciones, es decir, en su mismo constituir-se. ${ }^{4}$ Lo que Agamben llama el "íntimo entrecruzamiento entre ser y vivir". ${ }^{5}$

Nos gustaría argumentar aquí que es posible leer estos movimientos no solo en aquellos textos que tienen una impronta marcadamente autobiográfica -pongamos por caso el corpus estudiado por Giordano, de los relatos de Hebe Uhart a los diarios de Rodolfo Walsh-, sino también en un conjunto de ficciones más "puras" en las que el foco no está puesto sobre la experiencia íntima de un yo sino, de modo más oblicuo o distante, sobre la ambigüedad de la relación entre vida biológica y vida personal. Son textos en los que la incertidumbre no contamina los movimientos del yo, sino en los que directamente cuestiona su posibilidad de constitución, algunas veces recurriendo a formas de lo inhumano -el animal, el monstruo, el espectro-, otras tocando zonas en las que se puede apreciar la distancia entre lo humano y el lenguaje -la infancia, la locura, la experiencia de las drogas, la agonía-. Todas estas desfiguraciones atraviesan, ciertamente, a la literatura contemporánea, acompañando las sucesivas y cada vez más profundas crisis que el discurso humanista ha ido sufriendo, y proponiendo formas de imaginar eso que, siguiendo a Friedrich Nietzsche, Foucault ha caracterizado como la muerte del hombre. En los últimos tiempos, la literatura ha llevado al límite algunas de esas experiencias, escapando por completo al registro alegórico y centrando la mirada en el problema de lo viviente. Como si la pregunta por la dimensión política de la vida propuesta por el pensamiento foucaultiano hubiera hecho eco en la literatura, despertando inquietudes acerca de su dimensión artística. ¿Cómo se escribe, cómo se cuenta una forma-de-vida? ¿Qué le sucede al que cuenta, a esa subjetividad corpórea, cuando intenta contarla? ¿Qué rol cumplen en esos relatos los cuerpos? ¿Cómo son representados y cómo participan en la elaboración de una perspectiva en las narraciones? $\mathrm{O}$, en términos barthesianos: ¿qué tipo de ecuaciones se producen entre "la Frase y el Cuerpo"?.

\footnotetext{
4 “Pero qué significa constituir-se? Recordemos el constituir-se visitante o el pasear-se con el cual Spinoza [...] ejemplificaba la causa inmanente. La identidad entre activo y pasivo se corresponde con la ontología de la inmanencia, con el movimiento de la autoconstitución y de la autopresentación del ser, en el que no solo es imposible distinguir entre agente y paciente, sujeto y objeto, constituyente y constituido, sino también en el cual medio y fin, potencia y acto, obra e inoperosidad se indeterminan. La práctica de sí, el sujeto ético foucaultiano es esta inmanencia: el ser sujeto como pasear-se. El ser que se constituye en la práctica de sí no permanece -o no debería permanecer- nunca por debajo o antes de sí, no separa -o no debería separar nunca de sí un sujeto o una 'sustancia', sino que permanece inmanente a sí, es su constitución, y no cesa de constituir-se, exhibir-se y usar-se como agente, visitante, paseante, amante" (Agamben 2017: 200-201).
}

5 "¿Qué significa, pues, on existe? La existencia -este concepto en todo sentido fundamental de la filosofía primera de Occidente- tiene que ver acaso constitutivamente con la vida. "Ser -escribe Aristóteles- para los vivientes significa vivir". Y, siglos después, Nietzsche precisa: "Ser: no tenemos de ello otra representación que vivir". Sacar a la luz -por fuera de todo vitalismo- el íntimo entrecruzamiento de ser y vivir: esta es hoy, por cierto, la tarea del pensamiento (y de la política)" (Agamben 2017: 17).

${ }^{6}$ En los cursos y seminarios que dieron lugar a la edición de La preparación de la novela, Barthes reintroduce el problema de la relación del escritor con el cuerpo. Se detiene en la alimentación, las enfermedades, la farmacopea, la vestimenta, la casa que se habita, los horarios de trabajo. Una verdadera biopolítica (afirmativa) de la creación. 
Este estado de la ficción latinoamericana reciente tiene como correlato, de modo previsible, la multiplicación de lecturas críticas que ponen en contacto a la literatura con el pensamiento biopolítico. ${ }^{7}$ Es posible deslindar, para pensar mejor sus argumentos, dos grandes modos de intervención: se registra, por un lado, un marcado interés por estudiar desde dicha perspectiva las huellas políticas, económicas, sociales y culturales de la Conquista, partiendo de la hipótesis de que la biopolítica, en tanto forma de regulación de los cuerpos y las conductas, es connatural al proceso colonizador y, por tanto, al surgimiento de los estados latinoamericanos, que verán la luz bajo la impronta de una racialización ya instituida. ${ }^{8}$ Esta perspectiva se apoya generalmente en el concepto de representación; es decir, se identifican en la tradición literaria y, de modo más general, en la cultura latinoamericana, un conjunto coherente de imágenes, metáforas o alegorías de la violencia ejercidas -en un primer momento por el poder colonial y, más tarde, por los Estados nacionales- sobre individuos y comunidades. Estas lecturas permiten cartografiar la impronta del pensamiento biopolítico en la imaginación colectiva, así como también reconstruir una historia simbólica de los procesos de colonización y descolonización material e imaginaria en nuestro continente. Se analizan los avatares de cuerpos -individuales y colectivos- deshumanizados, degradados, desalmados, abandonados a su -mala- suerte, mutilados, enfermos, desaparecidos; la miseria urbana y suburbana, las dictaduras y sus vestigios, la violencia neoliberal, la marginalización de los inmigrantes, la discriminación racial, de género, de clase. La Historia y las historias que se cuentan están, desde este punto de vista, escritas en los cuerpos.

Por otro lado, es posible identificar un modo de abordaje crítico -que, ciertamente, muchas veces convive con el que acabamos de mencionar- más enfocado en la experimentación formal -aunque tal vez "formal" resulte, como veremos, poco satisfactorio o insuficiente para nombrar los movimientos que intentaremos circunscribir- que van, muchas veces, a contramano de la categoría de representación. En la lectura de las ficciones -no importa si su registro es predominantemente realista, como en el caso de las novelas de losi Havilio, o si tiene una atmósfera fantástica o alucinatoria, como en las novelas de Alejandra Tarazona, Ariana Harwicz y Diamela Eltit- el lenguaje, el de la obra y el de los personajes, es concebido no como rasgo distintivo de la humanidad, es decir, como una característica que separa al sujeto de su vida corporal, sino, por el contrario, como una parte constitutiva del cuerpo. Lenguaje y cuerpo están, en estas experimentaciones, íntimamente unidos y regidos por el ritmo de la vida.

La relación cuerpo-lenguaje que se desprende de dicha mirada crítica se identifica de modo bastante riguroso con la noción de "sujeto corpóreo nómada" formulada por Braidotti, en tanto en ella se ponen en contacto dos zonas que, en el pensamiento humanista, transitan carriles paralelos. El cuerpo es, en ese con-

\footnotetext{
7 Véanse Ostrov (2016), Rodríguez (2016a, 2016b, 2017), Giorgi (2014), Solodkow (2015), Martínez García (2017).

${ }^{8}$ Un buen ejemplo de este tipo de abordaje es el que proponen los editores del volumen Heridas abiertas. Biopolítica y representación en América Latina (Moraña y Sánchez Prado 2014).
} 
texto, "un lugar de transiciones y tramitaciones: es un espacio intermedio, donde se activan afectos y se estructuran influencias que desplazan la distinción entre el interior y el exterior del sujeto" (2018: 38). Esas tramitaciones dependen, en gran medida, de la memoria -recordemos el valor que tiene en el pensamiento nietzscheano la dinámica memoria/olvido como una forma de reencuentro con la animalidad humana- (Lemm 2010: 209-263), pero de una memoria que no está solamente ligada a la conciencia, en tanto relato de lo sucedido, sino que se vincula también a la capacidad sensible de retener el pasado. "El cuerpo es una entidad dinámica y móvil, provista de una memoria encarnada, una inteligencia de la materia carnal que, como enseña Bergson, está conectada con la memoria, es decir, con la capacidad de acordarse. Recordar quiere decir saber repetir, reencontrar en el espacio encarnado del tiempo vivido: es una forma de repetición vital que no debe nada a la conciencia y mucho, en cambio, a la sensibilidad". El cuerpo, desde este punto de vista, esa materia provista de memoria que, gracias a la capacidad de recordar y, por lo tanto, de repetir, "consigue permanecer fiel a sí misma, a través de los múltiples cambios y las diversas influencias sufridas" (Braidotti 2018: 38).

El dispositivo de lectura de la biopoética, que se propone sumar herramientas a esta segunda vertiente crítica, está orientado precisamente a leer en las ficciones las formas que asumen esos cuerpos pensantes $y$, para usar una expresión de Tununa Mercado, "en estado de memoria". En las imbricaciones entre lenguaje y forma-de-vida se recorta un objeto -la escritura biopoética- que, al mismo tiempo, pone a pensar a la teoría.

\section{LA PALABRA ENCARNADA}

Me doy cuenta, me doy cuenta, me contesta mi madre mientras busca mi mano, me toma la mano y me acaricia los dedos, aún no podemos poner en marcha las mutuales. La historia no está preparada para las mutuales de la sangre o las mutuales del cuerpo. Todavía no contamos con las condiciones. Pero lo vamos a conseguir. Quizás en ¿cuánto? ¿Unos doscientos años más? ¿no crees?, o cien o doscientos años más vamos a promover las mutuales del cuerpo, miles de mutuales del cuerpo, lo haremos cuando comprendamos de manera exacta cómo circula la sangre y el sitio preciso donde se produce el prolijo corte de los dedos.

Sí, madre, sí. En cuatrocientos o quinientos años vamos a fundar las mutuales del cuerpo.

Pero, ¿qué haremos con los fans y con el ímpetu terrible de las barras?

No sé, tenemos que pensar, que pensar, que seguir pensando.

¿Continuar pensando qué?, me pregunta mi madre.

Los orificios del cuerpo, mamá, los hoyos que tiene.

Diamela Eltit, Impuesto a la carne

Si el cuerpo es precisamente aquello que, gracias al trabajo de la memoria, hace posible la relación entre las personas y las cosas, ¿cómo podría, entonces, no producir pensamiento? Desde este punto de vista, las escrituras del cuerpo serían una serie de ejercicios creadores en los que la vida corporal -la del escri- 
tor, la de los personajes, la del lector- no es entendida como testimonio de un conjunto de condiciones externas - una superficie sobre la que se imprimen las huellas de la realidad-, sino como un campo de fuerzas al interior del cual el mundo toma forma. A la caída del par bíos/zoé le corresponde, así, la de la oposición persona/cosa, solo que aquí el tertium resultante no es la forma-de-vida sino el cuerpo, ese "tejido de nexos simbólicos solo en el interior de los cuales la realidad adquiere consistencia" (Esposito 2016: 108). ${ }^{9}$

En las ficciones de Havilio, Tarazona, Harwicz y Eltit, así como también, con diversos matices y orientaciones, en la producción reciente de otros novelistas latinoamericanos, como Ana Paula Maia (Entre rinhas de cachorros e porcos abatidos y De gados e homens) o Maximiliano Barrientos (En el cuerpo una voz), el trabajo sobre el lenguaje produce una intensificación de la ambigüedad, es decir, un borramiento de la dualidad cuerpo/pensamiento, con la consecuente emergencia de cuerpos pensantes: el de una chica embarazada en trance de convertirse en reptil (El animal sobre la piedra); el de una madre y una hija que, literalmente, no terminaron de cortar el cordón umbilical (La débil mental); el de otra madre y el de otra hija que, una dentro de la otra, conversan desde hace doscientos años (Impuesto a la carne); el de una protagonista sin nombre que, transitando una vida desesperante, ensaya un tono apático, anónimo, despersonalizado (Opendoor y Paraísos); ${ }^{10}$ los de hombres que en su trabajo cotidiano en un crematorio, un matadero o una estación de bomberos, experimentan en carne propia la desintegración de lo vivo, su devenir carne o ceniza, su mutilación, desorganización o desaparición (Entre rinhas de cachorros e porcos abatidos, De gados e homens); el de unos hermanos abandonados a la mera supervivencia física o el de un prisionero obligado a comer carne humana en una Bolivia post apocalíptica (En el cuerpo una voz). Todas estas narraciones pueden ser leídas como investigaciones sobre la capacidad de la escritura para producir un pensamiento del cuerpo -como pensar "acerca de" y como pensar impersonal- a través de la elaboración de voces y personajes que, con su hacer o con su no hacer, desdibujan la distinción entre lo que es -las personas-y lo que no es -las cosas-. Por eso no hay en los textos una exacerbación de lo corporal como unidad o plenitud vital; por el contrario, el procedimiento consiste en poner en entredicho la existencia de un cuerpo homogéneo, identificable, es decir, de un organismo. Esa desintegración permite que en ocasiones se perciba la emergencia de una vitalidad que no se puede asignar a ningún viviente; eso sucede cada vez que una voz no atina a decir yo, cada vez que una descripción corporal pierde de vista la especificidad humana, cada vez que un diálogo se funde con el continuo del relato, desenfocando al sujeto de la enunciación, cada vez, en fin, que la prosa se flexiona para que allí emerja un cuerpo desorganizado, despersonalizado, un cuerpo pensante.

\footnotetext{
9 Añade Esposito, reseñando la postura de Spinoza: "Así como no existen cosas fuera de la conciencia que las comprende, no existen conciencias que precedan la relación constitutiva con el mundo. Lo que hay al principio y al final del proceso no es la iluminación de un sujeto de conocimiento, sino la potencia infinita de la vida" (2016: 109).

10 Para una ampliación de este punto, véase Yelin (2015b).
} 
Podría ser útil aquí, por supuesto, la expresión "cuerpo sin órganos" que Gilles Deleuze y Félix Guattari (1988) tomaron prestada de Antonin Artaud, en tanto se trata, más bien, de cuerpos-fuerzas que se manifiestan como pura potencia: poder de afectar y de ser afectados por otros objetos y por otros cuerpos. El cuerpo sin órganos es una "conexión de deseos, conjunción de flujos, continuum de intensidades" (166), es decir, una práctica o un conjunto de prácticas tendientes a la desindividualización a través de diversas formas de contacto. La agresividad, el hambre, el deseo o el miedo son modalidades de esas interacciones que las ficciones continuamente escenifican; sin comentarlas, explicarlas, sin extraer de ellas enseñanzas o teorías; simplemente procurando que la escritura haga sensible el trabajo de esas fuerzas para, de ese modo, devolver el discurso al territorio de lo corporal. El cuerpo sin órganos se produce mediante un trabajo de experimentación, de conexión con potencias que producen una desorganización de los sentidos. En las narraciones a las que nos acabamos de referir, las relaciones entre las voces y las cosas no son nunca consideradas como el resultado de un encuentro entre personajes y objetos acabados sino más bien como la emergencia de una zona compartida -un cuerpo sin órganos- en la que todo toma forma de una sola vez. Los textos se abocan a nombrar los efectos de esos roces y los pliegues que se producen, señalando las zonas en las que la vida se vuelve alternativa o simultáneamente cognoscible -humana- e irreconocible -anónima, animal, muda, fantasmática, desnuda.

Los registros de los sentidos juegan allí un papel primordial: los olores, de modo muy prominente, esas micropartículas que se adhieren al cuerpo, que se vuelven parte de él y lo pegan, a su vez, a una historia. Es el olor de los muertos en En el cuerpo una voz: "¿Qué es lo que siente ahora que yo digo que mil personas fueron carneadas y echadas al fuego? ¿Qué ve cuando yo digo mil personas fueron descueradas y devoradas por los hombres del general en la comuna La Penca?", pregunta, en uno de los capítulos-testimonio Lydia Álvarez. Y se responde enseguida: "Nada, es un número nomás. El olor es otra cosa. El olor, a diferencia de sus rostros, es lo que persiste. Sudo el olor de los quemados. Está en mis dedos, en mi pelo. Lavo y lavo pero no se va de allí" (Barrientos 2018: 79). Ocupan también un lugar relevante los sonidos, que se presentan como materia continua, oscilante entre el sentido y el sinsentido; a veces es posible indentificar una voz, que luego se deshace y se vuelve un ruido, o se convierte en un estímulo para otros sentidos del narrador: "Comenzó como un ruido cuando orinaba en el monte, tenía veintidós años y fue convirtiéndose en mensajes concretos, en pulsiones. Me permitió estar en ella, me permitió refugiarme en su ruido. Susurros. Mandatos. Su espesura es casi una luz" (171). Al igual que en el horadamiento de la distinción entre bíos y zoé mediante la producción de cuerpos pensantes, en el mismo sentido se puede leer la insistencia en el borramiento de la frontera entre logos y phoné: el grito que puede volverse palabra para deshacerse nuevamente en una experiencia corporal: "Su grito resonó y se expandió por el canal más sensible e histerizado de mi oído y después de herir mi audición, ella susurró de manera consistente: Solas en el mundo. Su murmullo asoló mi espalda y luego repasó el milimétrico contorno de mi cara" (Eltit 2010: 11). 
Y están también las texturas -cada superficie merece atención, descripción, produce efectos-, los sabores, la distancia, el contacto con la propia piel o la proximidad de otros cuerpos intensifican esas sinuosidades del lenguaje, crean ritmos que se ajustan a los movimientos corporales. La narradora de Opendoor embarazada y sola en una casa de campo, describe así su enajenación, producto de la marihuana y la excitación, desdoblando el agente de las acciones, separando el cuerpo en dos dimensiones discernibles, que se corresponden con el uso de la primera y la tercera persona: los dedos que hacen, que producen efectos sobre esa otra dimensión de cuerpo, que percibe y reacciona. La escena se cierra con una imagen de animalización, deriva necesaria del relato de una experiencia impersonal:

Me paso el día sola, no me muevo y a veces, de tanto fumo, como le dicen en el campo, se me va la cabeza, pierdo noción, me cuelgo. Todo se vuelve oscuro, denso, gelatinoso, todo pasa por mis dedos que me arañan la piel, fuerte, con la ilusión de atravesar la carne, y yo ahí dejo de ser, dejo de actuar, me dejo llevar, acostada, parada, la panza presionando contra la pileta del baño, de loza gruesa, fría, pampeana, y no paro, me río sola, bailoteo, tiemblo un poco, y no paran los dedos, como si no fueran míos, de frotar el clítoris, el botón, de enroscar los pelos que cubren la concha, de frotar, y de meterse, uno, dos, tres, todos los que puedo, sudo como loca, y los otros dedos se meten por otras partes, masajeándome el culo, untando el ano con el flujo que resbala por la raya, y un charquito ocre, lindo, transparente, se estira sobre las sábanas de Jaime que se tragan lo que él no, lo que le da asco, y el olor a campo, a pasto húmedo, a luciérnagas, a parraseca, a ligustrina recién rebanada, y a los frutales, nísperos, quinotos, higos, el olor a barro mojado, el olor a polen, todos esos olores, tan patrios, se mezclan con los míos, hirviendo, como los de una gata en celo, una gata loca, desquiciada, que no puede más, que se arrastra, que acaba por enésima vez, a lo bestia, con los ojos turbios, deshecha de tanta paja. (Havilio 2006: 174-175)

El cuerpo erotizado produce un tránsito hacia una experiencia de sí que desorganiza el esquema corporal interno y la relación del cuerpo con el espacio. La narradora-bebé de La débil mental dice al inicio de su relato alucinado: "Me invento una vida en las nubes sentada en mi clítoris. Vibro, me agito, me trato con morfina en los dedos y durante ese lapso, todo está bien. Mi mano adentro es mil veces su cara dentro de mí, cuánto se puede poseer una cara, cuánto se puede meter una cara en el sexo" (Harwicz 2014: 7-8). La voz que narra es aquí, además, la de alguien que aún no habla, es una voz de nadie que, con ese solo recurso, debe hacerse una vida; para eso tiene que registrar lo que puede experimentar. En la novela, así como también en Impuesto a la carne, las vicisitudes corporales del vínculo madre-hija desmantelan la lógica del cuerpo como propiedad personal; el cuerpo es en ellas cualquier cosa menos garantía de autonomía, unidad, individualidad. Es un territorio común, siempre en disputa, caótico y enfermo de un mal irreconocible, doloroso y desesperante. Un mal que pone en movimiento la narración y se identifica de modo más o menos explícito con el paso del tiempo, con sus efectos sobre la materia viva. Aquí también la es- 
critura produce un desdoblamiento: hay un cuerpo exterior, visible, y un cuerpo interior que produce efectos sobre el primero, que trabaja silenciosamente en su destrucción. La imagen recupera la duplicidad entre "vida animal" o de relación (l'animal existant au-dehors) y vida orgánica (l'animal existant au-dedans) teorizada por Xavier Bichat en sus Recherches physiologiques sur la vie et sur la mort a principios del siglo XIX y, como apunta Agamben, extensamente difundida e instrumentalizada por la medicina moderna..$^{11}$ Una vida animal definida por sus relaciones con el mundo exterior y una vida interior que se identifica con lo que Aristóteles caracterizó como vida nutritiva, principio que define -aunque él mismo no pueda ser definido más que por una función- y aúna a todo el espectro de lo viviente. Esa división entre vida vegetativa y vida de relación, que atraviesa todos los imaginarios acerca del comportamiento y las taxonomías de lo vivo, trabaja también en la ficción, produciendo imágenes y relatos de cuerpos fragmentados, descontrolados, enajenados. Esa "vida otra" que las narradoras denuncian como afección constituye, al mismo tiempo, el motor de las narraciones. Lo que les sucede a los cuerpos es, en gran medida, el efecto del funcionamiento, oscuro y sigiloso, de esa vida vegetativa, no subjetivada ni subjetivable:

\begin{abstract}
Estamos hospitalizadas en un sector de nosotras mismas. El cuerpo de mi madre que yace dentro de mi cuerpo arde (de manera anarquista) de la cabeza a los pies. Tengo definitivamente dos anatomías, una, la más destruida y emotiva, está a la vista de todos, cualquiera puede verla y evaluarla, ese cuerpo es perturbador y ocupa demasiado espacio, pero mi otro cuerpo contiene el lugar del dolor orgánico que circula y se desplaza, duele, hiere al cuerpo visible, lo ataca desde sitios inesperados, en cierto modo me humilla, aunque esta es una expresión demasiado dramática, porque no se trata de un envilecimiento, sino de la suma destructiva de años de enfermedades. (Eltit 2010: 127)
\end{abstract}

Las imágenes recurrentes de un cuerpo -o de sus partes- dentro de otro cuerpo borran la distinción entre el adentro y el afuera. En La débil mental, los cuerpos de la madre y de la hija están también íntimamente imbricados, y la alternancia entre el relato del adentro y el afuera es disuelta a través de la sintaxis, que incrusta diálogos y pensamientos, como una sucesión de enunciados desapropiados. Este procedimiento tiene como efecto la disolución de la distinción entre el relato de hechos objetivos y la descripción de las percepciones subjetivas. Los hechos y los objetos no pertenecen a un contexto preexistente, sino que cobran sentido como restos de la experiencia presente.

EL TELÉFONO, MAMÁ. Ya caímos. Ya estamos de nuevo ordenando la alacena y barriendo, los huevos calientes riendo en la sartén. Dónde está. ¿Cómo querés la cocción? No hagas que te mire de nuevo. No voy a dártelo, no voy a ceder.

\footnotetext{
11 "Los éxitos de la cirugía moderna y de la anestesia se basan precisamente, entre otras cosas, en la posibilidad de dividir y, a la vez, articular los dos animales de Bichat. [...] Y todavía hoy, en las discusiones sobre la definición ex lege de los criterios de la muerte clínica, es un reconocimiento ulterior de esta nuda vida - desconectada de toda actividad cerebral y por así decirlo de todo sujeto- la que decide si un cuerpo puede considerarse vivo o debe ser entregado a la peripecia extrema de los transplantes" (Agamben 2005: 27-28).
} 


\begin{abstract}
Miro los cacharros colgando que pusimos con tanto esfuerzo. Miro los azulejos pegados uno contra otro. Miro los muros y los cimientos, los pedazos de pan. Dámelo, ya. Por qué querés irte de nuevo, estamos saliendo las dos adelante, sin ayuda del doctor Míster cuchillo, solas en medio del vejestorio, lo estamos logrando y el día se pone lindo así. ¿Picnic? Te dejo la hamaca. Dámelo antes de que los huevos estén pasados y vos llorando como siempre frente al plato frío. ¡Debería freírte ese teléfono de mierda! Dámelo ya mismo. Debería metértelo en el horno. Como quieras, entonces, pero bajo amenaza, y sale de la cocina las manos empapadas y entra en la oscuridad del pasillo y vuelve a salir a la luz del salón, que sin embargo ahora es oscuro y me lo tira. (Harwicz 2014: 18)
\end{abstract}

Madre e hija en una cocina que no necesita de una descripción porque toma forma a través de la fricción de esos dos cuerpos, de su historia compartida, del presente y el futuro -los cacharros que ellas colgaron, los azulejos pegados uno contra otro, los muros y los cimientos de la casa, los pedazos de pan, el huevo frito que se ríe sonoramente en la sartén, el ruido del teléfono que desata la escena-. La prosa convierte el mundo en pura subjetivación, al tiempo que desubjetiviza a los personajes al pegarlos al contexto, al encarnarlos en cuerpos que perciben y piensan, que deshacen la frontera entre el allá y el acá, entre la oscuridad del pasillo y la luz de salón, "que sin embargo ahora es oscuro". Los diálogos también son incorporados en ese espacio intersticial que no pertenece íntegramente a la conciencia, ni tampoco al mundo. El diálogo, como el cuerpo, está en medio, anulando el vacío, la distancia que se abre entre los hablantes cada vez que una voz toma cuerpo. Esa continuidad entre ruido y habla, entre diálogo y narración, entre segunda y tercera persona, tiene lugar, evidentemente, en la prosa, pero se origina en una transformación del punto de vista de la escritura o, para decirlo con mayor precisión, en una modificación del vínculo entre escritura y vida. Ya no se escribe la vida, sino que es una vida la que escribe.

Estos experimentos de desapropiación del cuerpo, de la voz y de la palabra, están, entonces, íntimamente vinculados a la asunción de una perspectiva corpórea, a la creación de una mirada producida por el ojo del cuerpo, que reemplaza o eclipsa el ojo de la mente (Esposito 2016: 111) y altera sensiblemente la percepción del entorno. El cuerpo-fuerza redibuja, así, la realidad sensible, la vuelve extraña, ajena, novedosa. Los bordes y los límites de las cosas se vuelven también inconsistentes. La narradora en proceso de metamorfosis de El animal sobre la piedra da buena cuenta de esa experiencia:

Voy a explicar a estas alturas lo que veo en el mundo. Las cosas exteriores no son como las sabía. Los objetos son transparentes, como si fuesen hechos de aire, su consistencia no es la que conocía. Por ejemplo: las sillas están detenidas en el vacío. No hay en los objetos un comienzo y un final, se encuentran unidos sin que se pueda definir uno sin otro. Quizá mis primeros atisbos sobre esta situación ocurrieron cuando mis párpados adquirieron transparencia. (Tarazona 2011:78)

Al igual que en las historias de animales de Kafka, la voz que narra expone no solo la falta de contenido del mundo sino también el vacío que hay tras su propia emisión: solo hay voz; detrás de ella, nada. Como en las "Investigaciones 
de un perro", en "La madriguera" o en "La metamorfosis", relatos en los que un discurso inasignable discurre acerca de la inefabilidad del entorno, en las narraciones a las que nos referimos, nadie habla. Nadie dice algo. ${ }^{12}$ Las narradoras de Harwicz, Eltit, Tarazona y Havilio se aventuran en viajes de de-subjetivación (devenir bebé, devenir-reptil, devenir-feto, devenir-anónima). Si el proceso de subjetivación conceptualizado por Foucault supone una serie de procedimientos por medio de los cuales el sujeto llega a observarse, analizarse y descifrarse a sí mismo en un juego de verdad a través del cual establece una relación consigo mismo (Foucault 1984), estas narradoras vivencian, a contracorriente del mismo proceso, la imposibilidad del reconocimiento, es decir, el derrumbe de la ilusión de correspondencia entre el yo y el mundo. En efecto, las cuatro desnudan la inexistencia de una identidad que trascienda lo sensorial; ven y se ven con el ojo del cuerpo, una lente que abre el mundo como proceso de continua recreación. No es casual que sea recurrente, por tanto, la presencia de cuerpos en estado de gestación -gestantes o gestados-: la imagen de la vida produciendo nueva vida. Como en las narraciones de Copi o en las de César Aira-antecedentes latinoamericanos de estas nuevas poéticas de lo viviente-, en cada cuerpo anida el germen de otra vida posible, que a su vez puede engendrar una nueva, y así sucesivamente. De esas cadenas azarosas emerge la imagen de la vida como potencia infinita.

Tanto en estas ficciones, en las que el centro de la escena está ocupado por el proceso de de-subjetivación de las voces narradoras, como en aquellas en las que, dentro de un registro más bien realista, se cuenta el derrotero descarnado y alucinado de unos cuerpos deshumanizados (Maia, Barrientos), se puede leer una indagación de la vida como proceso anónimo, errático e incesante que subraya, por un lado, su dimensión ética y política y, por otro, su faceta inventiva: ellas son un campo fértil para la creación conceptual. Si aceptamos, siguiendo la conceptualización propuesta por Agamben, que la forma-de-vida es la emergencia del acontecimiento antropogénico -separación y rearticulación incesante de bíos y zoé-, la relación vida-escritura podría ser pensada como la intensificación, por medio de una serie de procedimientos específicos, de las condiciones para la percepción del pliegue, de la cesura que caracteriza a lo humano; allí residiría, precisamente, su poder destituyente: mostrar, hacer presente en el lenguaje lo que no puede ser pronunciado; señalar ese resto que no se deja capturar por los dispositivos, ese centro vacío que sostiene y regula el funcionamiento de la máquina antropológica. Parece lícito decir, por tanto, que sin afirmar ni negar nada, haciendo simplemente que lo humano se muestre como efecto precario del lenguaje, la literatura latinoamericana reciente interviene activamente en la discusión filosófico-política actual acerca del estatuto de lo viviente. En esas intervenciones el cuerpo no es solo un campo de batalla biopolítica, es también una herramienta transformadora, tal vez la única vía posible para rozar lo impensado.

\footnotetext{
12 Véase Yelin (2011).
} 


\section{OBRAS CITADAS}

Agamben, Giorgio (2005): Lo abierto. El hombre y el animal. Valencia, Pre-Textos.

- (2017): El uso de los cuerpos. Homo Sacer Iv 2. Buenos Aires, Adriana Hidalgo.

Barrientos, Maximiliano (2018): En el cuerpo una voz. Buenos Aires, Eterna Cadencia.

Barthes, Roland (2005): La preparación de la novela. Notas de cursos y seminarios en el Collège de France, 1978-1979 y 1979-1980. Buenos Aires, Siglo XXI.

Beaulieu, Alain (2012): Cuerpo y acontecimiento. La estética de Gilles Deleuze. Buenos Aires, Letra viva.

Belinsky, Jorge (2007): Lo imaginario. Un estudio. Buenos Aires, Nueva Visión.

Braidotti, Rosi (2006): Transposiciones. Sobre la ética nómada. Barcelona, Gedisa.

— (2018). Por una política afirmativa. Itinerarios éticos. Barcelona, Gedisa.

Deleuze, Gilles (1987); La imagen-tiempo. Estudios sobre cine vol. 2. Buenos Aires, Paidós.

Deleuze, Gilles; Guattari, Félix (1988): "28 noviembre 1947 - ¿Cómo hacerse un cuerpo sin órganos? Mil mesetas. Capitalismo y esquizofrenia. Valencia, Pre-Textos.

Eltit, Diamela (2010): Impuesto a la carne. Buenos Aires, Eterna Cadencia.

Esposito, Roberto (2011): El dispositivo de la persona. Buenos Aires, Amorrortu.

- (2016): Las personas y las cosas. Buenos Aires, Eudeba.

Foucault, Michel (2002): Historia de la sexualidad, 1. La voluntad de saber. Buenos Aires, Siglo XXI.

Giordano, Alberto (2008): El giro autobiográfico en la literatura argentina actual. Buenos Aires, Mansalva.

Giorgi, Gabriel (2014): Formas comunes. Animalidad, cultura, biopolítica. Buenos Aires, Eterna Cadencia.

Harwicz, Ariana (2014): La débil mental. Buenos Aires, Mar dulce.

Havilio, losi (2006): Opendoor. Buenos Aires, Entropía.

- (2012): Paraísos. Buenos Aires, Mondadori.

Link, Daniel (2009): "Yo" No Retornable, n. 3. Dossier "La imagen lo es todo". Disponible en <http://www.no-retornable.com.ar/v3/dossier/link.html>.

Maia, Ana Paula (2011): Carvão animal. Rio de Janeiro, Record.

- (2013): De gados e homens. Rio de Janeiro, Record.

Martínez García, Miguel Ángel (coord.) (2017): Monográfico "Mundo hospital: enfermedad y formas de vida en las sociedades actuales", Kamchatka, vol. 10, pp. 5-423.

Moraña, Mabel e Ignacio Sánchez Prado (eds.) (2014): Heridas abiertas. Biopolítica y representación en América Latina. Madrid/Frankfurt, Iberoamericana/Vervuert.

Ostrov, Andrea (coord.) (2016): Cuerpos, territorios y biopolíticas en la literatura latinoamericana. Buenos Aires, NJ Editor.

Rodríguez, Fermín (2016a): "Hacer vivir afuera. En la frontera de la vida". Badebec, vol. 6, n. ${ }^{\circ} 11$, pp. 22-41.

— (2016b): "Cuerpo y capitalismo: el trabajo de la violencia y el miedo". Estrategias n. ${ }^{\circ}$ 4 , pp. 43-46.

— (2017): "Señales de vida: ficciones y territorios en crisis". 452 $F$, n. ${ }^{\circ} 16$, pp. 43-61.

Solodkow, David (2015). Ficción biopolítica y eugenesia en el Martín Fierro. Bogotá, Ediciones Uniandes. 
Tarazona, Daniela (2011). El animal sobre la piedra. Buenos Aires, Entropía.

Yelin, Julieta (2015a): "Biopoéticas para las biopolíticas. Una introducción". Uni(+di)versidad, n. 3 , pp. 1-10. Disponible en <http://www.puds.unr.edu.ar/wp-content/ uploads/2016/05/Biopo\%C3\%A9ticas-para-las-biopol\%C3\%ADticas.-Unaintroducci\%C3\%B3n-1.pdf>.

- (2015b): "Una vida nueva. Imágenes y pensamiento de la animalidad en Opendoor y Paraísos de Iosi Havilio". En Iván Ávila (coord.): La cuestión animal(ista). Bogotá, Desde Abajo.

_ (2016): "Biopolíticas de la interpretación", Estação literária, n. 17, pp. 28-39. Disponible en <http://www.uel.br/pos/letras/EL/vagao/EL17-Art2.pdf>.

(2017): "La lente biopoética de Mario Bellatin". En Alexandra Navarro y Anahí Gabriela González (eds.): Es tiempo de coexistir. Perspectivas, debates y otras provocaciones en torno de los animales no humanos. La Plata, Editorial Latinoamericana Especializada en Estudios Críticos Animales, pp. 117-129. Disponible en <https://www.academia. edu/35450777/Es_tiempo_de_coexistir_perspectivas_debates_y_otras_provocaciones_en_torno_a_los_animales_no_humanos>. 